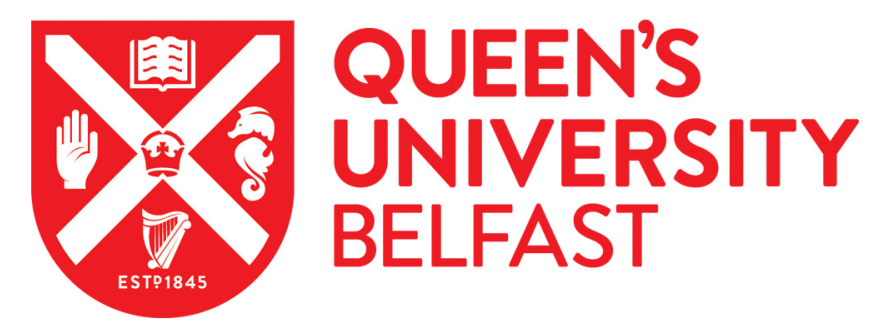

\title{
Gender Differences in the Perceptions of Genuine and Simulated Laughter and Amused Facial Expressions
}

McKeown, G., Sneddon, I., \& Curran, W. (2015). Gender Differences in the Perceptions of Genuine and Simulated Laughter and Amused Facial Expressions. Emotion Review, 7(1), 30-38.

https://doi.org/10.1177/1754073914544475

Published in:

Emotion Review

Document Version:

Early version, also known as pre-print

Queen's University Belfast - Research Portal:

Link to publication record in Queen's University Belfast Research Portal

Publisher rights

Copyright to author

\section{General rights}

Copyright for the publications made accessible via the Queen's University Belfast Research Portal is retained by the author(s) and / or other copyright owners and it is a condition of accessing these publications that users recognise and abide by the legal requirements associated with these rights.

Take down policy

The Research Portal is Queen's institutional repository that provides access to Queen's research output. Every effort has been made to ensure that content in the Research Portal does not infringe any person's rights, or applicable UK laws. If you discover content in the Research Portal that you believe breaches copyright or violates any law, please contact openaccess@qub.ac.uk. 


\section{Gender Differences in the Perceptions of Genuine and Simulated Laughter and Amused Facial Expressions}

\begin{tabular}{|c|c|}
\hline Journal: & Emotion Review \\
\hline Manuscript ID: & EMR-13-606.R2 \\
\hline Manuscript Type: & Original Manuscript \\
\hline Date Submitted by the Author: & 08-Apr-2014 \\
\hline Complete List of Authors: & $\begin{array}{l}\text { McKeown, Gary; Queen's University Belfast, School of Psychology } \\
\text { Sneddon, Ian; Queen's University Belfast, School of Psychology } \\
\text { Curran, William; Queen's University Belfast, Department of Psychology }\end{array}$ \\
\hline Area/Discipline: & evolutionary < psychology, social < psychology \\
\hline Keywords: & laughter, simulation, evolution, gender \\
\hline Abstract: & $\begin{array}{l}\text { This review addresses gender differences in laughter and smiling from an } \\
\text { evolutionary perspective. Laughter and smiling can be responses to } \\
\text { successful display behavior or signals of affiliation amongst conversational } \\
\text { partners-differing social and evolutionary agendas mean there are different } \\
\text { motivations when interpreting these signals. Two experiments assess } \\
\text { perceptions of genuine and simulated male and female laughter and } \\
\text { amusement social signals. Results show male simulation can always be } \\
\text { distinguished. Female simulation is more complicated as males can } \\
\text { distinguish cues of simulation yet judge simulated signals to be genuine. } \\
\text { Females judge other female's genuine signals to have higher levels of } \\
\text { simulation. Results highlight the importance of laughter and smiling in } \\
\text { human interactions, use of dynamic stimuli, and using multiple } \\
\text { methodologies to assess perception. }\end{array}$ \\
\hline
\end{tabular}

\section{SCHOLARONE ${ }^{m}$ \\ Manuscripts}


Gender Differences in the Perceptions of Genuine and Simulated Laughter and Amused Facial Expressions

Gary McKeown, Ian Sneddon, William Curran

School of Psychology, Queen's University Belfast

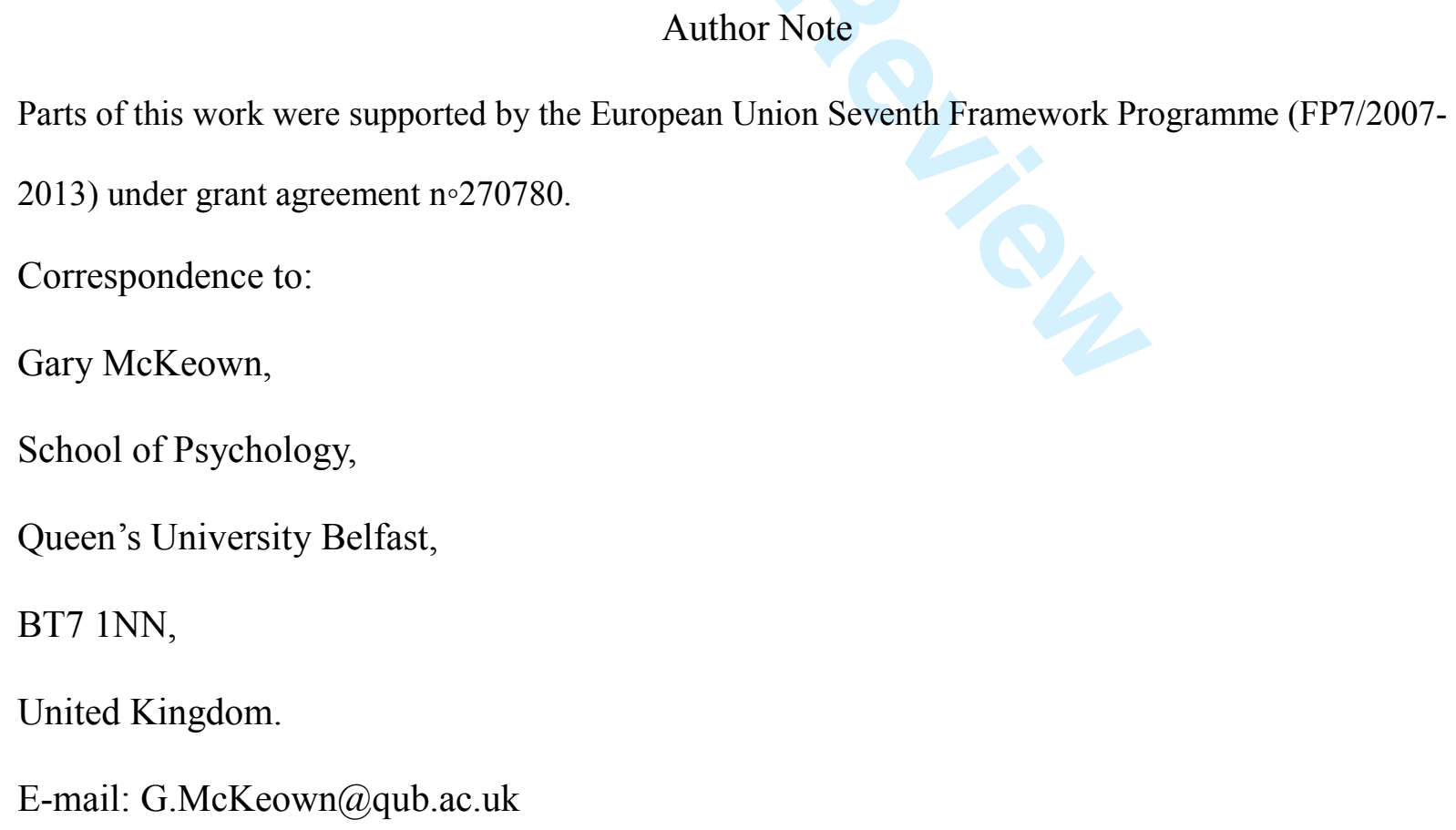




\begin{abstract}
This review addresses gender differences in laughter and smiling from an evolutionary perspective. Laughter and smiling can be responses to successful display behavior or signals of affiliation amongst conversational partners-differing social and evolutionary agendas mean there are different motivations when interpreting these signals. Two experiments assess perceptions of genuine and simulated male and female laughter and amusement social signals. Results show male simulation can always be distinguished. Female simulation is more complicated as males can distinguish cues of simulation yet judge simulated signals to be genuine. Females judge other female's genuine signals to have higher levels of simulation. Results highlight the importance of laughter and smiling in human interactions, use of dynamic stimuli, and using multiple methodologies to assess perception.
\end{abstract}

Keywords: Laughter, Simulation, Evolution, Social Signals, Gender 
Gender Differences in the Perceptions of Genuine and Simulated Laughter and Amused Facial Expressions

Expectations about gender differences in human communication differ dependent on which theoretical account is adopted. Evolutionary perspectives provide strong reasons to expect large gender differences in many aspects of human behavior. Trivers' (1972) parental investment theory and its applications to humans in sexual strategies theory (Buss \& Schmitt, 1993) and strategic pluralism theory (Gangestad \& Simpson, 2000) argue for varying degrees of conflict and cooperation between the sexes. Much evidence shows gender differences exist where they would be expected-in aspects of mating and investment in child rearing for instance (Buss \& Schmitt, 1993; Schmitt, 2005). Human communication and signaling behaviors in these circumstances would be expected to come under strong selection pressures. This often occurs in animal communication (Laidre \& Johnstone, 2013; Searcy \& Nowicki, 2005); the risk of being deceived into mating with a lower quality partner often leads to costly signaling and the development of handicaps that ensure the honesty of a signal, as in the peacock's tail (Loyau, Saint Jalme, Cagniant, \& Sorci, 2005).

However, social and cultural perspectives tend to view gender differences in human social signaling as minimal, particularly in areas beyond those associated with sexuality (Fine, 2010). For instance, the gender similarity hypotheses (Hyde, 2005) suggests a striking similarity between the genders in most but not all psychological variables; $78 \%$ of the variables tested in a meta-analysis showed only small effect sizes. Unsurprisingly, differences were found in measures related to sexuality; some motor performance abilities; and physical aggression. Hyde (2005) also reported a moderate effect size difference in smiling-drawn from another meta- 
analysis by LaFrance, Hecht, and Paluck (2003); laughter was not examined and no difference in levels of happiness was found (Pinquart \& Sörensen, 2001; Wood, Rhodes, \& Whelan, 1989). Based on ideas prevalent in behavioral ecology and evolutionary psychology Fridlund (1994) argued that smiling-indeed all facial expressions-should be viewed through the lens of social communicative display rather than as an "emotional readout" of felt happiness-the view favored by the school of thought traditionally attributed the label "evolutionary" within the study of emotion (Ekman, 1994). Parkinson (2005) provides a review of these differing evolutionary accounts and suggests both are problematic in varying degrees.

In a similar vein to Fridlund (1994) a recent evolutionary account by Vigil (2009)-the socio-relational framework of expressive behaviors (SRFB)-emphasizes that, to be adaptive, expressivity must enhance the signaler's fitness. This is achieved by signaling social bonding and affiliation or social distancing and avoidance. Individuals possess and must display a social attractiveness quality, their "reciprocity potential," which has two components, capacity and trustworthiness. Capacity cues advertise resources-genetic worth, food provision, protective abilities, or socio-political opportunities-while trustworthiness cues advertise the likelihood of reciprocal altruism (Vigil 2007). Capacity displays tend to create status-seeking and dominance communications whereas trustworthiness displays create more affiliative and submissive communications. According to Vigil (2009) the evolutionary origins of gender differences in emotional communication arise due to the hominin tendency towards male philopatry in which females left natal social groups to join groups with males bonded by kinship. Males could rely on inclusive fitness factors (Hamilton 1964) to ensure allegiance and could consequently concentrate on competitive and dominance communication activities; females-with no kin 
selection advantage-had to spend more time bolstering affiliation. Laughter from this perspective displays affiliative goals, trustworthiness and is a somewhat submissive social signal.

Vigil (2009) claims there is strong evidence for sexual dimorphism in emotional expressivity and perception, but others-who favor social role explanations-argue that the evidence is much more equivocal (Fischer, 2009; Fugate, Gouzoules \& Feldman Barrett 2009). LaFrance et al. (2003) reject evolutionary explanations preferring socio-cultural accounts for gender differences in smiling; effect sizes reduced when participants believed they were not being observed, suggesting greater adherence to gender norms with knowledge of observation. They characterize evolutionary accounts as claiming that sex differences "evolved early in human history" implying that these selection pressures have long since ceased to exert an influence. This view often indicates an assumption that survival pressures-predation, foraging, seeking shelter-primarily shaped humans behavior; survival pressures have changed substantially over human history but they tend to affect female and male hominins equally. Crucially, there is little reason to think that conflict based on reproduction and parental investment (Trivers, 1972) have ceased to be an issue, leaving behaviors frozen since Paleolithic times. Additionally, these sexual selection pressures are much more likely to involve intraspecies socio-communicative signals. These pressures cause us to seek higher social status and the reproductive benefits that accrue with elevated social rank-as outlined by the social brain hypothesis (Byrne \& Whiten, 1988; Dunbar, 1998)-and the more direct pressures generated by mate selection (Miller, 2001). Also some modern evolutionary viewpoints that focus on the evolution of communication-both non-verbal and verbal-are less likely to view cultural components as isolated and separate from evolutionary explanations. Miller (1999), Chater and Christiansen (2010) and McKeown (2013) place an emphasis on cultural learning as part of an 
evolving communicative process which subverts the distinction between evolutionary and cultural accounts and instead advocate an integration between cultural and evolutionary components; there is also a growing recognition of the importance of gene-culture coevolution (Gintis, 2011). In essence, cultures can change the adaptive niches in which organisms find themselves and a key part of getting genes into the next generation is being able to function adequately within learned cultural norms; this is especially likely to be the case for gender norms. So adherence to and knowledge of gender norms may be an important part of an evolutionary account.

An evolutionary account proposed by McKeown (2013) places communication more centrally in human evolution than the provision of information in the form of capacity or trustworthiness cues argued by Vigil (2009). McKeown views the main function of human communication as the display of mind-reading abilities. This is similar to a capacity cue but displaying mind-reading abilities indicates socio-political prowess in itself rather than simply providing information about socio-political opportunities. In McKeown's account mind-reading abilities became sexually selected in humans and needed to be displayed. In order to display mind-reading abilities one must have knowledge of a potential partner's mind; this results in the two main goals of human communication, display and alignment; these take primacy over the more traditionally assumed function of human communication-the exchange of useful information. Mind-reading skills are displayed both non-verbally and verbally, but successful display requires a large degree of mental pre-alignment. Communicators must be aligned with the communicative expectations of their partners; they are motivated to display in order to elevate status and attract mates, and motivated to observe or listen in order to improve alignment. McKeown (2013) argues that this need for mental alignment creates an active process resulting 
in similarity between genders in areas where goals are not directly conflicting (Hyde, 2005).

Much of human communication concerns alignment and positive affiliative signals sustain communication to aid alignment. These cues are similar to trustworthiness cues (Vigil, 2007; 2009), with a stronger emphasis on active mental alignment than simple affiliation. Humans must train themselves-and be trained by kin-on the culturally appropriate circumstances in which communicative signals should be delivered providing a strong motivation for the perpetuation of cultural gender roles in social signaling. A lack of awareness of cultural communicative expectations displays poor mind-reading and social awkwardness, decreasing one's value as a mate or ally.

When the opportunity arises humans produce displays. This mind-reading display view of human communication means that many behaviors not previously viewed as communicative can be seen as possessing communicative intent. Non-verbal examples include cooperating, preempting another's goals and aiding them, or giving gifts-including providing useful information. A cooperator or giver signals knowledge of a receiver's desires (McKeown, 2013). Both verbal and non-verbal displays, including humor, have been suggested to be mental fitness indicators (Howrigan \& MacDonald, 2008; McKeown, 2013; Miller, 2001) and smiling and laughter are relevant adaptive signals (Mehu, Little \& Dunbar, 2008). Fitness indicators differ from survival pressure adaptations as they serve to advertise fitness to other animals-often within sexual selection signaling situations. Mental fitness indicators are mental characteristics that indicate fitness to potential mates, allies, and rivals; these include intelligence, verbal proficiency, creativity, kindness and empathy, and humor (Miller, 2008).

Successful displays are met with positive affiliative social signals-in the case of humor smiles and laughter are the most obvious. Laughter, in particular, has a dual role serving both as 
a response signaling the appreciation of humor, and as a social signal indicating a desire to remain affiliated (Glenn, 2003; Provine, 2000). Given the importance of knowing and being able to interpret such signals appropriately as signs of sexual interest or desire for affiliation we might expect that humans would be particularly well equipped at distinguishing between genuine and false laughter-although not necessarily consciously. However, more nuanced sociocommunicative views of emotional expressivity challenge what is meant by genuine and false communication.

\section{Honesty, truth, falsehood, and the display of mind-reading abilities}

Truth and falsehood in social signals are often confusing concepts and depend strongly on the assumptions made about the purpose or function of communication. A common view in non-verbal communication research is that expressions signal a felt emotion-they serve as an emotional readout. This view allows expressions to take a bivalent logic, they are either true or false depending on whether the expression matches the felt emotion. However, emotional readout views are difficult to reconcile with evolutionary perspectives as they often ignore the requirement that adaptive signals must benefit the sender (Dawkins \& Krebs, 1984).

Straightforward provision of information about the sender's state would lead to exploitation and be quickly extinguished. Receivers must also benefit from signals and manipulative unreliable signals are soon ignored. These factors typically lead to the development of costly signaling within animal communication resulting in hard-to-fake signals (Zahavi \& Zahavi, 1997; Searcy \& Nowicki, 2005). It appears that such hard-to-fake signals influencing authenticity and trustworthiness do exist in certain circumstances within human social signaling and they seem to possess an involuntary or unbidden nature as part of what makes them hard-to-fake; these are 
signals such as blushing (Dijk, Koenig, Ketelaar, \& De Jong, 2011), tears (Hasson, 2009), and smiling (Krumhuber, Manstead \& Kappas, 2007; Centorrino, Djemai, Hopfensitz, Milinski, \& Seabright 2010). In smiling research, the widespread reliance on morphological markers such as Duchenne components to determine authenticity (probably to the neglect of other indicators of smile authenticity) has been strongly questioned (Krumhuber \& Manstead, 2009; Maringer, Fischer, Krumhuber \& Niedenthal, 2011). An increased role for context (Bourgeois \& Hess 2008) and temporal dynamics in interpreting smiles has been recognized (Hess \& Kleck 1990; Krumhuber, Manstead, Cosker, Marshall, Rosin \& Kappas, 2007); these factors may be even more important in ascertaining decisions of authenticity in laughter where temporal dynamics have been shown to have an important function (Smoski \& Bachorowski, 2003; Bryant \& Aktipis, 2014).

Despite this evidence for hard-to-fake signals some human communication situations do not fit this pattern. In verbal communication, for example, "white lies," involve the use of false information to avoid hurting someone's feelings, or in cases of indirect speech and plausible deniability, incomplete information is provided to explore other people's feelings (Pinker, Nowak, \& Lee, 2008).

When human communication is viewed as having broader socio-communicative aimswhether showing capacity and trustworthiness cues (Vigil, 2009) or display and alignment (McKeown, 2103)-the authenticity issue becomes more complex. From a displaying mindreading abilities perspective, white lies and plausible deniability can be explained as displaying knowledge of someone else's feelings, or ensuring that negative impressions are not communicated and alignment goals are not compromised. Niedenthal, Mermillod, Maringer and Hess (2010) address the complexities of authenticity in smiling in their simulation of smiles 
model (SIMS) paper; when considering social motives and other's feelings they suggest three categories of attribution should be considered, the smiler's felt state, the intended outcome of the smile interaction for the smiler, and the intended outcome of the smile interaction for the smile perceiver. These categories are most likely relevant in understanding laughter too.

Laughter in its most intense forms appears to have a reliable and hard-to-fake quality. If a laugh simply signals the appreciation of a successful humor display then a false laugh is one made in response to a humorous display that was not found to be humorous-a deceptive signal of appreciation. The need to distinguish genuine appreciation of humor from deceptive appreciation of humor may be enough for the hard-to-fake qualities of laughter to have developed. However, laughter comes in a range of intensities and only high intensity laughter seems to exhibit this hard-to-fake quality. In addition laughter appears to have many more functions than simply signaling appreciation of humor, it appears to have strong social bonding properties and many functions in smoothing the flow of human interactions (Glenn, 2003; Holt, 2010, 2011; Provine, 2000).

At lower levels of intensity laughter seems to function in a similar way to indirect speech or the white lie-while it does not seem to be an entirely involuntary honest signal, a more volitional laugh in a socially appropriate place ensures that alignment goals and affiliation are not compromised and serves to display knowledge of cultural conventions. Choosing not to produce socially appropriate laughter could be taken as an insult or shows that the non-laugher is unaware of cultural norms-the absence of a culturally appropriate signal can itself be a strong signal. Laughter in these more voluntary circumstances is perhaps not false, but it is not entirely genuine either. 
Grammer (1990) suggests the vagueness or ambiguity of non-verbal signals, and laughter in particular, allow them to function in a manner like indirect speech-they permit non-committal communication that allows misunderstandings to be easily rectified without losing face. According to Grammer, this vagueness makes laughter a useful signal in mating contexts-it can be a polite aversive signal of disinterest or, at high intensity, a strong signal of interest. This retains the possibility of a non-verbal plausible deniability-ambiguity creates a high likelihood of misinterpretation that permits a retraction of meaning either verbally or by altering subsequent non-verbal signals. Outside of mating contexts polite social laughter may signal a desire to continue a conversation serving alignment or affiliation goals.

Laughter can also be unambiguously false, where more exaggerated or attenuated laughter is produced than is appropriate for the context. Such laughter activates the neural circuitry associated with mentalizing (McGettigan et al., 2013), perhaps, as people assess the social motives of these laughs. Differentiating between genuine and false or inappropriate laughter may have important implications as people navigate their social hierarchies; the special role that laughter seems to play in mating contexts makes this especially relevant to gender differences in social signaling.

\section{The properties and evolution of laughter}

Laughter motivates us; we seek out behaviors, people and situations that make us laugh and relax when we laugh socially. Laughter's connection to humor is intriguing; although it is a low level reflex-like behavior, it is often emitted in response to the complex high-level cognition and contextual interpretation that is required to understand humor. Given a linguistic joke, responses occur within 700-1000ms and laugh-related physical responses follow quickly after 
(Juckel et al., 2011; Marinkovic et al., 2010). This reflex-like speed suggests an old evolutionary mechanism, but the connection with high level culturally contextualized cognition suggest it has retained important social signal functions into the modern era.

Laughter's origins appear to lie with social bonding behaviors in primates 1who make a "play face" and panting sounds while playing (Davila Ross, Owren, \& Zimmermann, 2009). Van Hooff (1972) suggests that laughter and smiling have different origins in primate displays; laughter originates in the relaxed open mouthed display or "play face," while smiling originates in the bared teeth display. These displays function as defensive, submissive, and friendly reassuring signals depending on the species and circumstances (Preuschoft \& van Hooff, 1997). Van Hooff (1972) suggests that despite their different origins they now function on something of a continuum. Possibly, evolution towards a continuum creates ambiguity allowing plausible deniability between genuine appreciation of humor and polite disinterest in mating contexts (Grammer 1990). Laughter is associated with social play situations in humans in the form of tickling where it serves as a social bonding signal, particularly in "roughhousing" play with children and there is some evidence for the use of tickling and mock aggression in adults in romantic situations (Ballard, Green, \& Granger, 2012). Gervais and Wilson (2005) have suggested an evolutionary pathway from this safe social bonding signal has led to the incorporation of the laughter social signal within human conversation both in a strong "felt" manner and a more utilitarian "polite" manner. Deliberate "polite smiling" may play a gender specific appeasement or affiliative role in the negotiation of dominance and status relationships in men. Mehu \& Dunbar (2008) found that young men produced more deliberate smiles in groups that also contained older men; the equivalent situation was not found in women. 
Gender differences have also been found in the production of laughter; Grammer and Eibl-Eibesfeldt (1990) found that same sex groups laughed more than mixed sex groups and women laughed more than men in mixed sex groups, and even more so when the group contained a man independently rated as attractive, implicating mating motives in mixed sex laughter signals. They also found that the amount a woman laughs is predictive of both women's and men's interest in dating. This may be related to the role of humor as a mental fitness indicator. Bressler and Balshine (2006) found that amongst students only women rating men's “autobiographical statements” found humor desirable. Bressler, Martin, and Balshine (2006) examined sex differences in preference for humor production and receptivity finding that women preferred men who produced good humor and men preferred women who appreciated good humor. Laughter seems to indicate receptivity to humor and may indirectly serve to signal interest as a potential partner. This may explain the reduced levels of laughter in mixed sex groups where the stakes are high and the interpretation of laughter can be more than just affiliative-the wrong interpretation or over effusive laughter can have important social consequences. Mehu's (2011) ethological study showed less evidence for gender differences in laughter, but it also noted that occurrences of high intensity laughter were rare in the analyzed data. While Mehu \& Dunbar (2008) found some evidence that laughter may have a role in sexual aspects of interactions they thought their evidence favored an intra-sexual regulation and affiliative role.

In the remainder of this paper we report on two experiments that address some of the issues raised in this brief review. They examine how perceptions of genuine and simulated 
laughter differ between genders and offer an initial attempt to provide a methodology to assess these issues.

\section{Experiments}

Volunteers-both women and men-were recorded as they produced either genuine or simulated smiles and laughter in response to watching an amusing video. Following Fridlund (1994) we view this as an "implicitly social" task, as viewers passively observe a social event; in these initial experiments we opted for the increased experimental control a video permits but accept that an active social event would be more desirable. Recordings of a fear inducing taskmore related to survival selection pressures-were used as a control group, however, the comparability of fear and amusement reactions is debatable and we report only minimal results for the fear task. We use the operational term simulation due to the noted complications that arise with the terms false or fake. We remind readers that that while our intention may have been to induce amusement, we have no objective means of knowing to what extent this was achieved in each case. As noted in the review, doubt has been cast on the relative importance of morphological aspects of smiles in relation to genuine and false distinctions and there are important but often-neglected roles for context and temporal dynamics. We choose not to prejudge what those cues may be and base our operational distinctions on the tasks the recorded volunteers were given-we use the operational terms "spontaneous task", "simulated task" and "amusement signals" to emphasize this point.

We are interested in how women and men perceive the amusement signals generated in these tasks. The simplest outcome would be that both women and men can tell when amusement 
signals are simulated in both sexes-a straightforward hypothesis that all laughs are hard-to-fake social signals.

However, as the theories outlined in the review suggest, we may expect differences between women and men in how they perceive laughter in the opposite sex and within sex. When men are being observed laughing-the ultimate possibility of physical aggression from men means that both sexes should be attuned to instances where men are genuinely laughing or simulating laughter; knowledge of men's affiliative intentions is important and signs of fake laughter may indicate risk of aggression.

When women are observed laughing-men should be assessing women's levels of interest as suggested by Grammer (1990) and genuine laughter would be more indicative of sincere interest. While Grammer has suggested that polite laughter could be interpreted as aversive, we note that men could also interpret simulated laughter as an indicator of interest-women laughing despite not being sincerely amused could signal interest using volitional social signals.

Where women are observing women laughing-two possible outcomes are predicted.

First, all laughter is perceived to be genuine-alignment goals may cause all laughter to be viewed as affiliative. Second, given the often reported general propensity for women to be more emotionally perceptive than men (Baron-Cohen \& Wheelwright, 2004; Donges, Kersting \& Suslow, 2012; Eisenberg \& Lennon, 1983) women may be able to distinguish genuine from simulated laughter in laughers of both sexes.

The two experiments used the same video clips, but two different techniques to assess the perception of laughter. First, rating continuous moment-by-moment simulation levels using a trace style annotation tool (Cowie, McKeown, \& Douglas-Cowie, 2012). Second, a summative rating after each clip had been watched in its entirety. 


\title{
General Method
}

\section{The stimulus recordings}

Eighteen (9 men, 9 women) university students (referred to as 'encoders') with no formal acting experience were video-recorded while taking part in an "implicitly social" amusement induction task (details of the fear task-the spider box task-can be found in Sneddon, McRorie, McKeown, \& Hanratty, 2012). In the spontaneous task participants watched a $2 \mathrm{~min} 31 \mathrm{~s}$ video clip-two individuals engaged in humorous conversation-extracted from an episode of Father Ted, a well-known UK and Ireland television comedy series (Baker, Shortt, Perkins, \& Lowney, 1996). Stimuli were 30s recordings of participants watching the same segment of the clip.

After completing the fear task and a short interlude, the encoders were asked to simulate the emotional experience of the amusement task by 'pretending' to experience what they had felt first time around. They watched a blank and silent screen on which the words 'something funny' appeared timed to coincide with the studio laughter on the original soundtrack. Each of the 18 encoders, therefore, contributed 4 stimulus recordings: spontaneous amusement; spontaneous fear; simulated amusement and simulated fear.

\section{Experiment 1-Continuous Ratings of Simulation}

\author{
Method \\ 60 participant "decoders" (27 women and 33 men) were recruited by opportunistic \\ sampling. Individual decoders viewed all four of the recordings contributed by each of 3 male \\ and 3 female encoders (a total of 24 recordings). Previous research indicated that 20 decoders \\ yielded stable ratings of similar 30 second recordings of induced emotion (McKeown \& Sneddon, \\ 2014).
}


Each decoder had the 24 recordings allocated to them randomly presented on a laptop computer using the ActTrace variant of a continuous annotation program called GTrace (Cowie et al., 2012). Participants provided ratings of simulated amusement displayed by the encoder using a mouse and horizontal slider interface (for an example of a valence based version of the interface see Sneddon, McKeown, McRorie, \& Vukicevic, 2011). The slider scale was anchored at the left end by the text 'No simulation of emotion' with 'Extreme simulation of emotion' at the right. Decoders based ratings on visual cues only, as all recordings were played with muted sound. The ActTrace program records the slider handle position on a $0-100$ scale every $25 \mathrm{~ms}$. A single average score was then calculated across the 30 seconds of each recording. Each decoder rated 3 video clips of each instance of the variables encoder sex $\times$ spontaneity/simulation $\times$ task.

Decoders initially used the trace tool while viewing a practice recording as often as they wished. When ready, participants rated their 24 allocated recordings. They could redo the rating if desired with data from the final attempt used in the analysis, in practice, this facility was rarely used.

\section{Results}

The 'Amusement Task'. A 2 (decoder sex) $\times 2$ (encoder sex) $\times 2$ (simulation) repeated measures ANOVA indicated a main effect showing decoder ability to discriminate between recordings of simulated from spontaneous amusement signals, $F(1,58)=18.75, p<0.001$, correctly rating higher overall levels of simulation. Figure 1a indicates that this ability was not distributed evenly across the conditions. Interest lies in the different perceptions of the men and women to the same sets of stimuli-the four columns on the Encoder Sex axis. Men decoders correctly rated simulation as significantly higher in the simulated condition for both sexes (encoding men: 
$\mathrm{t}(32)=2.08, \mathrm{p}=0.046$; encoding women: $\mathrm{t}(32)=3.62, \mathrm{p}=0.001)$. However, while women decoders correctly rated men encoders as showing significantly lower simulation in the spontaneous clips $\mathrm{t}(26)=2.58, \mathrm{p}=0.016$, they failed to discriminate women's spontaneous from simulated clips. Women in both the spontaneous and simulated instances were treated as having high levels of simulation.

The 'Fear Task'. A $2($ decoder sex $) \times 2($ encoder sex $) \times 2$ (simulation) repeated measures ANOVA indicated that in the 'fear task' all decoders failed to discriminate between recordings of spontaneous and simulated emotion.

\section{Discussion}

The first experiment raises two interesting points. First, men decoders seem to be capable of distinguishing between genuine and simulated amusement signals in both men and women. This meets with the most basic of our predictions-laughter is hard-to-fake, the tasks are relatively easy and it is obvious which signals are spontaneous or simulated. However, the same pattern does not occur for women. Women seem to distinguish between spontaneous and simulated amusement signals generated by men-as predicted; they do not distinguish between spontaneous and simulated amusement signals generated by other women. The more detailed prediction for women observing other women was that simulated amusement signals would be viewed as spontaneous; the results here show the opposite pattern-that women perceive spontaneous amusement signals as simulated. These are tentative first results and caution is recommended, however we felt that they warranted further investigation. 


\section{Experiment 2-Summative Judgements of Simulation}

Experiment 1 provided preliminary evidence for gender differences that were surprising in that men seemed to outperform women in distinguishing between spontaneous and simulated laughter when observing females. Experiment 2 sought to replicate the experimental design of study 1 but with a modified task. In place of a trace task that assessed the moment-by-moment cues of simulation participants instead watched a video clip in its entirety and gave a summative judgment of the perceived level of simulation at the end. We hypothesized that we would replicate the findings of the Experiment 1 but were also cognizant that the tasks were different.

\section{Method}

95 participants (58 women; 37 men) were recruited via Amazon Mechanical Turk. Each participant (decoder) was asked to view 24 of the recordings described above (the four stimulus recordings contributed by 6 randomly selected encoders).

Decoders watched each 30 second clip and then rated the level of simulation on an 11 point (zero to ten) scale anchored by the terms 'no simulation' and 'extreme simulation' before repeating the process for the next clip. The order of clip presentation was a random and unique for each decoder.

\section{Results}

The 'Amusement Task'. A 2 (decoder sex) $\times 2$ (encoder sex $) \times 2$ (simulation) repeated measures ANOVA again indicated a main effect showing decoder ability to discriminate between spontaneous and simulated amusement signals, $F(1,93)=23.72, p<0.001$. Decoders judged that the simulated clips showed higher overall simulation levels than the spontaneous recordings. However, as with the continuous ratings and as Figure $1 \mathrm{~b}$ shows, planned comparisons revealed 
that this discriminative ability was not evenly distributed across the conditions. Decoding men again correctly rated encoding men as showing higher simulation in the simulated clips, $\mathrm{t}(36)=3.57, \mathrm{p}=0.001$, but when using summative judgments, they failed to discriminate between spontaneous and simulated signals displayed by women, judging them to have shown low simulation in both situations.

Decoding women showed the same pattern of response as they did when using continuous ratings. They correctly rated encoding men as showing significantly lower simulation in the spontaneous clips, $\mathrm{t}(57)=3.15, \mathrm{p}=0.003$, but failed to discriminate between recordings of spontaneous and simulated amusement signals for women encoders, again rating women in both situations as showing high simulation.

The 'Fear Task'. When using a summative judgment scale a $2($ decoder sex $) \times 2$ $($ encoder sex $) \times 2($ simulation $)$ repeated measures ANOVA indicated a main effect of discrimination between spontaneous and simulated emotion, $F(1,93)=21.86, p=0.01$. Both men and women decoders judged that simulation levels were higher in the simulated clips than the spontaneous clips.

\section{Discussion}

The summative task replicated the findings of experiment 1 for women decoders; they distinguished between spontaneous and simulated amusement signals in men but did not in women-again perceiving spontaneous amusement signals to be at similar levels to those of simulated amusement signals. 
The summative task did not produce a replication of results for men decoders. Men could distinguish between instances of genuine and simulated amusement signals in other men but not women. The direction of this lack of distinction is also interesting-men perceived women's simulated amusement signals to be at similar levels to their genuine amusement signals. This is the opposite direction from the manner in which women fail to distinguish between genuine and simulated amusement signals.

Using the summative measure, decoders in the 'Fear task' could correctly distinguish simulated from genuine signals, with no gender differences.

\section{General Discussion}

The simplest prediction was that decoders would differentiate between spontaneous and simulated amusement signals-suggesting that signals are hard-to-fake, and inauthenticity is easy to detect. However, the findings were more complicated than this. We also predicted, correctly, that both sexes would distinguish genuine from simulated amusement signals in men-possibly due to the ultimate sanction of physical aggression.

Unanticipated results arose in the perceptions of laughing women. Men's results were interesting as they differed across the two tasks. When using the more direct moment-by-moment trace task, men distinguished between women's genuine and simulated signals. We had hypothesized that it would be important knowledge for men-to gauge a potential romantic partner's level of interest (Grammer, 1990). However, in the summative task men seemed to assume that women's amusement signals were always genuine. We had addressed this possibility, that males may assume that any signal of interest is worthwhile whether it is genuine or not. One interpretation is that while males possess the cue information to enable 
differentiation, they choose not to use it when summing up an interaction. This supports error management theory (Haselton \& Buss, 2000) and may show evidence of the sexual overperception bias (Haselton, 2003). Although the information is available to males, it may be adaptive to make false-positive errors and assume genuine laughter, as shown in the summative task. Future research may include manipulations of mating motives, or emphasize laughter as an assessment of humor to further test this difference. Caution is necessary however, as a simpler interpretation is that this finding is a straightforward failure to replicate the first finding, especially as this was the only one of the planned comparisons that failed to replicate.

The results of women's perception of other women's amusement signals were not as predicted. We had predicted general affiliation-viewing all laughter as genuine-or better performance than men. However, in both tasks all amusement signals were viewed at high levels of simulation. Here we suspect that context is important; the women in the video clips are strangers, and women perceivers may adopt a general wariness of out-group women in line with theories highlighting intra-sexual competition between women (Vaillancourt, 2013). This also requires further research including manipulating the degree friendship with laughers. We would predict that where women feel they are rating friends the pattern would be similar to that of men perceiving women.

The fear results showed no gender differences, suggesting that signals related to survival selection pressures are likely to be similarly perceived by both women and men.

The use of dynamic stimuli and the different findings between the two tasks in some conditions have methodological ramifications. Relying on summative judgements-static images can be viewed as single frame summative judgements-as is common in the emotion literature 
may fail to reveal important aspects in the perception of non-verbal social signals. A broader repertoire of methodologies than the constant use of static images is recommended.

These experiments represented an initial attempt to assess gender differences in amusement signals using dynamic visual material, as such, they suffer a number of limitations. In particular, ecological validity and incorporation of contextual factors could be improved. Future experiments should attempt to induce stronger feelings of sociality, and manipulate the friendship levels between perceivers and laughers. Ideally an experiment would induce participants to feel as if they were rating laughter from a conversation they engaged in. Also the dependent measure is couched in terms of simulation, altering this to assess genuineness may prime a different set of cues. Perhaps the biggest limitation was using only the visual components of laughter with no auditory cues, the importance of which is well documented and has implications related to gender (Bachorowski \& Owren, 2001; Bryant \& Aktipis, 2014).

This review and initial findings reinforce the value of studying laughter and humor as points of conflict highlighting gender specific evolutionary goals. Gender differences in human interaction are seldom as simple as 'females are better than males at task A' or 'males are better than females at task B', and probably best not thought of in that manner. Instead, a more complex understanding of varying agendas and social goals that change with context is required. This certainly calls for moving beyond simple tasks involving static posed expressions of prototypical emotion, and probably even for moving beyond context-neutral, spontaneous, dynamic stimuli, to stimuli that incorporate context and that can realistically manipulate the agendas and goals of the participants.

\section{References}

Baker, H., Shortt, P., Perkins, G.P., \& Lowney, D.D. (1996) “Father Ted, Episode 1 Series 
2, 'Hell' [Situation Comedy]," Hat Trick Productions/Channel 4.

Ballard, M. E., Green, S., \& Granger, C. (2012). Affiliation, flirting, and fun: Mock aggressive behavior in college students. The Psychological Record, 53(1), 33-49.

Baron-Cohen, S., \& Wheelwright, S. (2004). The empathy quotient: an investigation of adults with Asperger syndrome or high functioning autism, and normal sex differences. Journal of Autism and Developmental Disorders, 34(2), 163-175.

Bourgeois, P., \& Hess, U. (2008). The impact of social context on mimicry. Biological Psychology, 77(3), 343-352.

Bressler, E. R., \& Balshine, S. (2006). The influence of humor on desirability. Evolution and Human Behavior, 27(1), 29-39. doi:10.1016/j.evolhumbehav.2005.06.002

Bressler, E. R., Martin, R., \& Balshine, S. (2006). Production and appreciation of humor as sexually selected traits. Evolution and Human Behavior, 27(2), 121-130. doi:10.1016/j.evolhumbehav.2005.09.001

Bryant, G. A., \& Aktipis, C. (2014). The animal nature of spontaneous human laughter. Evolution and Human Behavior. 35(4), 327-335. doi:10.1016/j.evolhumbehav.2014.03.003

Buss, D. M., \& Schmitt, D. P. (1993). Sexual strategies theory: An evolutionary perspective on human mating. Psychological Review, 100(2), 204-232.

Byrne, R. W., \& Whiten, A. (1988). Machiavellian Intelligence: Social expertise and the evolution of intellect in monkeys, apes, and humans. Oxford: Oxford University Press.

Centorrino, S., Djemai, E., Hopfensitz, A., Milinski, M. \& Seabright, P. (2010). Honest smiles as a costly signal in social exchange. Behavioral and Brain Sciences, 33(06), 439.

Chater, N., \& Christiansen, M. (2010). Language acquisition meets language evolution. 
Cognitive Science, 34(7), 1131-1157.

Cowie, R., Douglas-Cowie, E., Savvidou, S., McMahon, E., Sawey, M., \& Schroder, M. (2000). "FEELTRACE": An instrument for recording perceived emotion in real time. Presented at the Proceedings of the ISCA Tutorial and Research Workshop on Speech and Emotion, Newcastle, Northern Ireland, UK.

Cowie, R., McKeown, G., \& Douglas-Cowie, E. (2012). Tracing Emotion: An Overview. International Journal of Synthetic Emotions, 3(1), 1-17. doi:10.4018/jse.2012010101

Davila Ross, M., J Owren, M., \& Zimmermann, E. (2009). Reconstructing the evolution of laughter in great apes and humans. Current Biology, 19(13), 1106-1111.

De Jong, P. J., \& Dijk, C. (2013). Social Effects of Facial Blushing: Influence of Context and Actor Versus Observer Perspective. Social and Personality Psychology Compass, 7(1), 1326. doi:10.1111/spc3.12009

Dijk, C., Koenig, B., Ketelaar, T., \& De Jong, P. J. (2011). Saved by the blush: Being trusted despite defecting. Emotion, 11(2), 313-319. doi:10.1037/a0022774

Donges, U.-S., Kersting, A., \& Suslow, T. (2012). Women's Greater Ability to Perceive Happy Facial Emotion Automatically: Gender Differences in Affective Priming. PLoS ONE, 7(7), e41745. doi:10.1371/journal.pone.0041745.t004

Dunbar, R. I. M. (1998). The Social Brain Hypothesis. Evolutionary Anthropology, 6, 178-190.

Eisenberg, N., \& Lennon, R. (1983). Sex differences in empathy and related capacities. Psychological Bulletin, 94(1), 100.

Ekman, P. (1994). Strong evidence for universals in facial expressions: A reply to Russell's mistaken critique. Psychological Bulletin, 115, 268-268.

Fine, C. (2010). From Scanner to Sound Bite: Issues in Interpreting and Reporting Sex 
Differences in the Brain. Current Directions in Psychological Science, 19(5), 280-283.

Fridlund, A. J. (1994). Human facial expression: An evolutionary view. San Diego, CA, US: Academic Press.

Gangestad, S. W., \& Simpson, J. A. (2000). The evolution of human mating: trade-offs and strategic pluralism. Behavioral and Brain Sciences, 23(4), 573-87; discussion 587-644.

Gervais, M., \& Wilson, D. (2005). The evolution and functions of laughter and humor: A synthetic approach. Quarterly Review Of Biology, 80(4), 395-430.

Gintis, H. (2011). Gene-culture coevolution and the nature of human sociality. Philosophical Transactions of the Royal Society of London. Series B, Biological Sciences, 366(1566), 878888. doi:10.1098/rstb.2010.0310

Glenn, P. J. (2003). Laughter in Interaction. Cambridge: Cambridge University Press.

Grammer, K. (1990). Strangers meet: Laughter and nonverbal signs of interest in opposite-sex encounters. Journal of Nonverbal Behavior, 14(4), 209-236.

Grammer, K., \& Eibl-Eibesfeldt, I. (1990). The ritualisation of laughter.

Walter.A.Koch(ed.):Natürlichkeit der Sprache und der Kultur: acta colloquii - Bochum: ckmeyer 1990 (Bochumer Beiträge zur Semiotik; 18) ISBN 3-88339-738-5, pp 192-

214. 1-23.

Hamilton, W.D. (1964) The genetical evolution of social behaviour. Parts I and II. Journal of Theoretical Biology, 7, pp. 1-52.

Haselton, M. G. (2003). The sexual overperception bias: Evidence of a systematic bias in men from a survey of naturally occurring events. Journal of Research in Personality, 37(1), 3447.

Haselton, M., \& Buss, D. M. (2000). Error management theory: a new perspective on biases in 
cross-sex mind reading. Journal of Personality and Social Psychology (Vol. 78, pp. 81-91).

Hasson, O. (2009). Emotional Tears as Biological Signals. Evolutionary Psychology, 7(3), 363370.

Holt, E. (2010). The last laugh: Shared laughter and topic termination. Journal of Pragmatics, $42(6), 1513-1525$.

Holt, E. (2011). On the Nature of" Laughables": Laughter as a Response to Overdone Figurative Phrases. Pragmatics, 21(3).

Howrigan, D. P., \& MacDonald, K. B. (2008). Humor as a Mental Fitness Indicator. Evolutionary Psychology, 6(4), 652-666.

Hyde, J. S. (2005). The Gender Similarities Hypothesis. American Psychologist, 60(6), 581-592. doi:10.1037/0003-066X.60.6.581

Juckel, G., Mergl, R., Brüne, M., Villeneuve, I., Frodl, T., Schmitt, G., et al. (2011). Is evaluation of humorous stimuli associated with frontal cortex morphology? A pilot study using facial micro-movement analysis and MRI. Cortex, 47(5), 569-574. doi:10.1016/j.cortex.2010.04.004

Krebs, J. R., \& Dawkins, R. (1984). Animal signals: mind-reading and manipulation. Krebs, J. R., \& Davies, N. B. (Eds.). Behavioural Ecology: an evolutionary approach, 2, pp 380-402. John Wiley \& Sons

Krumhuber, E. G., \& Manstead, A. S. R. (2009). Can Duchenne smiles be feigned? New evidence on felt and false smiles. Emotion, 9(6), 807-820. doi:10.1037/a0017844

Krumhuber, E., Manstead, A. S., Cosker, D., Marshall, D., Rosin, P. L., \& Kappas, A. (2007). Facial dynamics as indicators of trustworthiness and cooperative behavior. Emotion, 7(4), 730. 
LaFrance, M., Hecht, M. A., \& Paluck, E. L. (2003). The contingent smile: A meta-analysis of sex differences in smiling. Psychological Bulletin, 129(2), 305-334. doi:10.1037/00332909.129.2.305

Laidre, M. E., \& Johnstone, R. A. (2013). Animal signals. Current Biology, 23(18), R829-R833. doi:10.1016/j.cub.2013.07.070

Loyau, A., Saint Jalme, M., Cagniant, C., \& Sorci, G. (2005). Multiple sexual advertisements honestly reflect health status in peacocks (Pavo cristatus). Behavioral Ecology and Sociobiology, 58(6), 552-557. doi:10.1007/s00265-005-0958-y

Marinkovic, K., Baldwin, S., Courtney, M. G., Witzel, T., Dale, A. M., \& Halgren, E. (2010). Right hemisphere has the last laugh: neural dynamics of joke appreciation. Cognitive, Affective, \& Behavioral Neuroscience, 11(1), 113-130. doi:10.3758/s13415-010-0017-7

McGettigan, C., Walsh, E., Jessop, R., Agnew, Z. K., Sauter, D. A., Warren, J. E., \& Scott, S. K. (2013). Individual Differences in Laughter Perception Reveal Roles for Mentalizing and Sensorimotor Systems in the Evaluation of Emotional Authenticity. Cerebral Cortex. doi:10.1093/cercor/bht227

McKeown, G. J. (2013). The Analogical Peacock Hypothesis: The Sexual Selection of MindReading and Relational Cognition in Human Communication. Review of General Psychology, 17(3), 267-287. doi:10.1037/a0032631

McKeown, G., \& Sneddon, I. (2014). Modelling continuous self-report measures of perceived emotion using generalized additive mixed models. Psychological Methods, 19(1), 155-174. doi: $10.1037 / \mathrm{a} 0034282$

Mehu, M., \& Dunbar, R. I. M. (2008). Relationship between Smiling and Laughter in Humans (Homo sapiens): Testing the Power Asymmetry Hypothesis. Folia Primatologica, 79(5), 
269-280. doi:10.1159/000126928

Mehu, M., Little, A. C., \& Dunbar, R. I. (2008). Sex differences in the effect of smiling on social judgments: An evolutionary approach. Journal of Social, Evolutionary, and Cultural Psychology, 2(3), 103.

Miller, G. F. (1999). Sexual selection for cultural displays. In R. Dunbar, C. Knight, \& C. Power (Eds.), The evolution of culture. Edinburgh U. Press.

Miller, G. F. (2001). The Mating Mind. London: Vintage.

Miller, G. (2008). Mating intelligence: Frequently asked questions. In Geher, G., \& Miller, G. (Eds.) Mating intelligence: Sex, relationships, and the mind's reproductive system, pp 367393. Lawrence Erlbaum Associates: New York.

Niedenthal, P. M., Mermillod, M., Maringer, M., \& Hess, U. (2010). The Simulation of Smiles (SIMS) model: Embodied simulation and the meaning of facial expression. Behavioral and Brain Sciences, 33(06), 417-433.

Parkinson, B. (2005). Do Facial Movements Express Emotions or Communicate Motives? Personality and Social Psychology Bulletin, 9(4), 278-311. doi:10.1207/s15327957pspr0904_1

Pinker, S., Nowak, M. A., \& Lee, J. J. (2008). The logic of indirect speech. Proceedings of the National Academy of Sciences of the United States of America, 105(3), 833-838. doi:10.1073/pnas.0707192105

Pinquart, M., \& Sörensen, S. (2001). Gender differences in self-concept and psychological wellbeing in old age: a meta-analysis. The journals of gerontology. Series B, Psychological sciences and social sciences, 56(4), P195-213.

Provine, R. R. (2000). Laughter: a scientific investigation. London: Faber and Faber. 
Puts, D. A. (2010). Beauty and the beast: mechanisms of sexual selection in humans. Evolution and Human Behavior, 31(3), 157-175. doi:10.1016/j.evolhumbehav.2010.02.005

Schmitt, D. P. (2005). Sociosexuality from Argentina to Zimbabwe: A 48-nation study of sex, culture, and strategies of human mating. Behavioral and Brain Sciences, 28(02), 247-275.

Searcy, W. A., \& Nowicki, S. (2005). The Evolution of Animal Communication: Reliability and Deception in Signaling Systems (pp. 1-285). Princeton: Princeton University Press.

Sneddon, I., McKeown, G., McRorie, M., \& Vukicevic, T. (2011). Cross-Cultural Patterns in Dynamic Ratings of Positive and Negative Natural Emotional Behaviour. PLoS ONE, 6(2), e14679.

Sneddon, I., McRorie, M., McKeown, G., \& Hanratty, J. (2012). The Belfast Induced Natural Emotion Database. IEEE Transactions on Affective Computing, 3(1), 32-41. doi:10.1109/TAFFC.2011.26

Trivers, R. L. (1972). Parental Investment and Sexual Selection. In B. Campbell (Ed.), Sexual Selection and the Descent of Man 1871-1971 (pp. 136-207). Chicago: Aldone Publishing Company. doi:10.1111/j.1420-9101.2008.01540.x

Vaillancourt, T. (2013). Do human females use indirect aggression as an intrasexual competition strategy? Philosophical Transactions of the Royal Society of London. Series B, Biological Sciences, 368(1631), 20130080. doi:10.1098/rstb.2013.0080

van Hooff, J. A. (1972). A comparative approach to the phylogeny of laughter and smiling. In R. A. Hinde (Ed.), Non-verbal Communication. Cambridge: Cambridge U. Press.

Vigil, J. M. (2007). Asymmetries in the friendship preferences and social styles of men and women. Human Nature, 18(2), 143-161.

Wacewicz, S., \& Żywiczyński, P. (2012). Human Honest Signalling and Nonverbal 
Communication. Psychology of Language and Communication, 16(2), 113-130. doi:10.2478/v10057-012-0009-5

Wood, W., Rhodes, N., \& Whelan, M. (1989). Sex differences in positive well-being: A consideration of emotional style and marital status. Psychological Bulletin, 106(2), 249-264. doi:10.1037/0033-2909.106.2.249

Zahavi, A. \& Zahavi, A. 1997. The Handicap Principle. New York: Oxford University Press. 
Figures
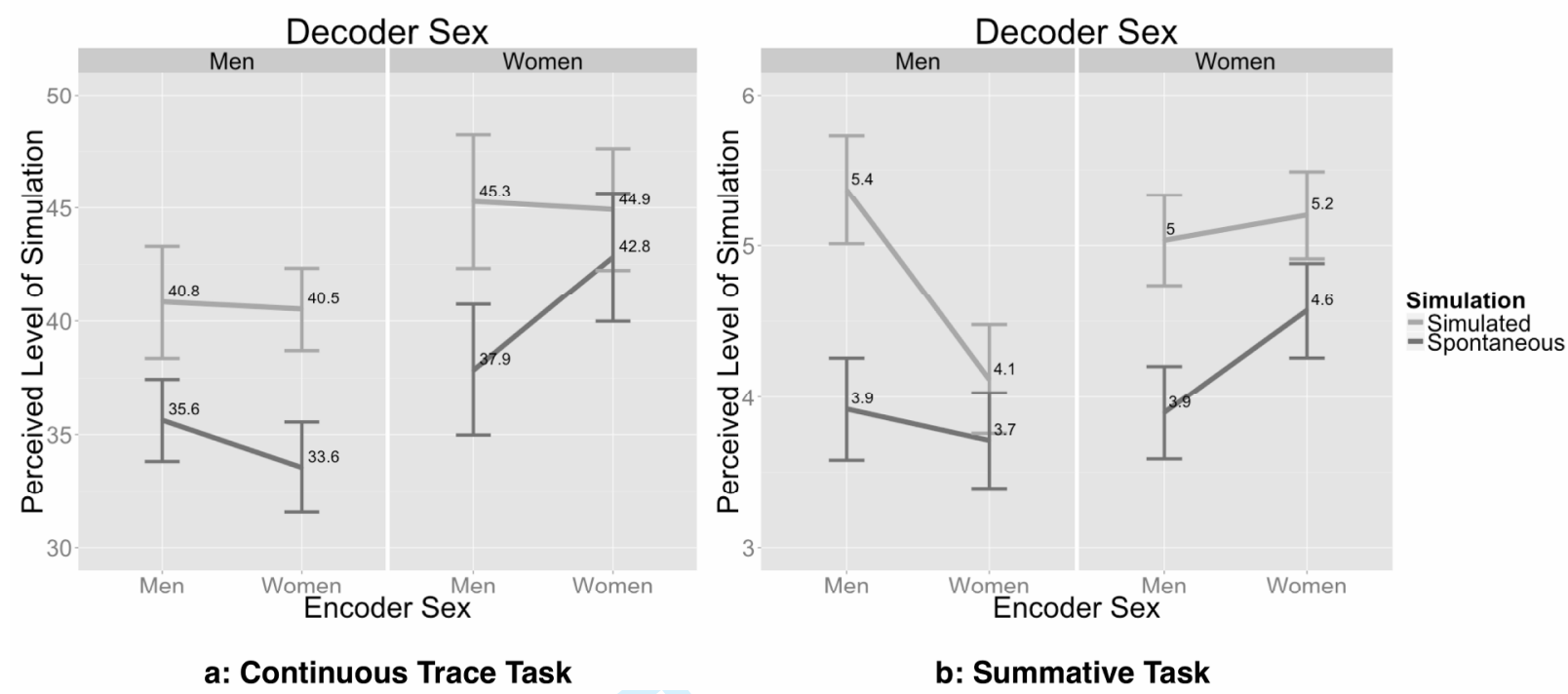

Figure 1. Perceived levels of simulation by men and women decoders viewing spontaneous and simulated laughter/amusement in both women and men encoders in a: the continuous trace task and b: the summative task. Error bars represent standard error and the data labels are the mean perceived level of simulation. 


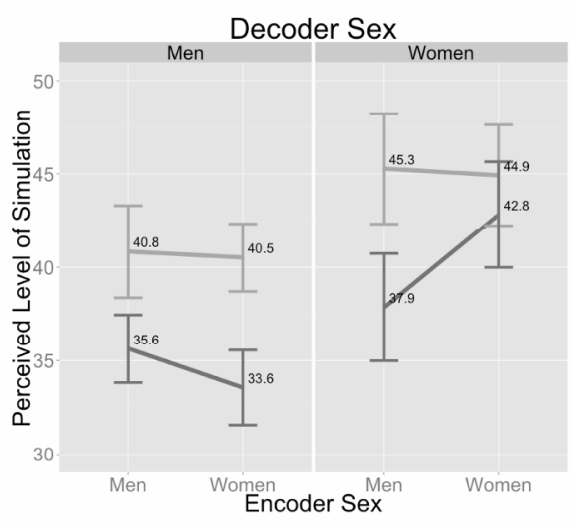

a: Continuous Trace Task

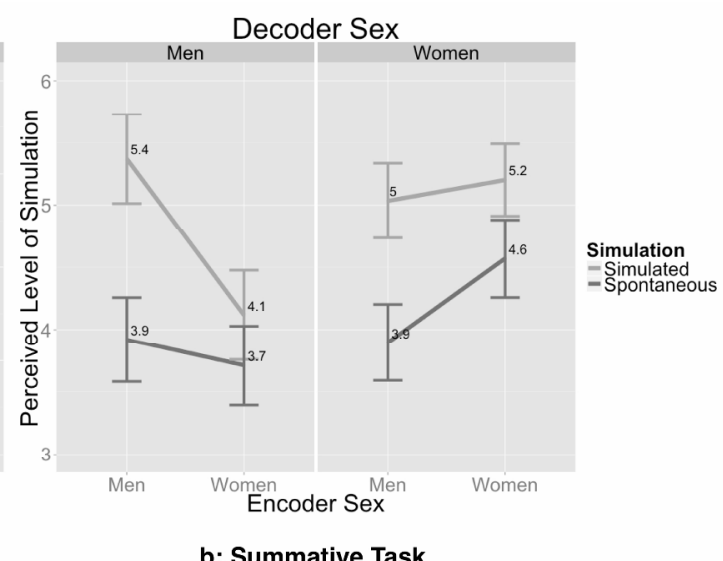

b: Summative Task

Figure 1. Perceived levels of simulation by men and women decoders viewing spontaneous and simulated laughter/amusement in both women and men encoders in a: the continuous trace task and $b$ : the summative task. Error bars represent standard error and the data labels are the mean perceived level of simulation.

$257 \times 112 \mathrm{~mm}(300 \times 300 \mathrm{DPI})$ 